\title{
Sexual Expression in Alberta's Continuing Care Homes: Capacity, Consent, and Co-decision-making
}

\author{
Julia Brassolotto, 닌 Lisa Howard, and Alessandro Manduca-Barone \\ Faculty of Health Sciences, University of Lethbridge
}

\begin{abstract}
RÉSUMÉ
Dans cet article, nous explorons le rôle des décideurs substituts (DS) en matière d'expression sexuelle pour les résidents en soins de longue durée ayant des déficiences cognitives. Nous examinons en quoi le rôle actuel des DS en Alberta favorise une approche « tout ou rien » de l'aptitude, en vertu de laquelle une personne est soit considérée apte pour prendre toutes les décisions la concernant, soit totalement inapte. Trois facteurs contribuent à la création d'un environnement dans lequel une approche « tout ou rien » peut influencer l'expression sexuelle des résidents. Il s'agit notamment du contenu de la législation en vigueur, du manque de ressources pour les DS et de la dynamique relationnelle entre les DS et le personnel soignant. Nous présentons un examen critique de la législation existante et des preuves empiriques liées aux défis qu'elle entraîne dans la pratique. Bien que nous concentrions sur le contexte albertain, il est probable que des problèmes similaires subsistent dans d'autres juridictions occidentales. Nous offrons plusieurs recommandations visant l'amélioration du soutien de l'autonomie sexuelle des résidents dans les soins continus et la prévention des écueils de l'approche « tout ou rien » en matière d'aptitude.
\end{abstract}

\begin{abstract}
In this article, we explore the role of substitute decision-makers (SDMs) in matters of sexual expression for continuing care residents with diminished cognitive capacity. We examine how Alberta's current use of SDMs can enable an "all-or-none" approach to competence, wherein a person either has capacity to make all decisions or is incapable of making any. Three factors facilitate an environment in which this approach can influence residents' sexual expression. These include the wording of current legislation, lack of resources for SDMs, and relational dynamics between SDMs and care staff. We provide a critical review of existing legislation and empirical evidence of its challenges in practice. Though we focus on the Alberta context, there is reason to believe that similar issues persist in other Western jurisdictions. We offer several recommendations for how we can better support residents' sexual autonomy in continuing care and avoid pitfalls of the "all-or-none" approach to competence.
\end{abstract}

Manuscript received: / manuscrit reçu : 14/10/2018

Manuscript accepted: / manuscrit accepté : 15/11/2019

Mots-clés: vieillissement, capacité, consentement, expression sexuelle, soins continus, démence

Keywords: ageing, capacity, consent, sexual expression, continuing care, dementia

La correspondance et les demandes de tirés-à-part doivent être adressées à: / Correspondence and requests for offprints should be sent to:

Julia Brassolotto, Ph.D.

Assistant Professor

Faculty of Health Sciences

University of Lethbridge

4401 University Drive

Lethbridge, Alberta T1K 3M4

(julia.brassolotto@uleth.ca)

Canadian Journal on Aging / La revue canadienne du vieillissement 40 (1) : 156-165 (2021)

Copyright $(9$ Canadian Association on Gerontology 2020. This is an Open Access article, distributed under the terms of the Creative Commons Attribution licence (http://creativecommons.org/licenses/by/4.0/), which permits unrestricted re-use, distribution, and reproduction in any medium, provided the original work is properly cited. 


\section{Introduction}

Many residents living in continuing care settings experience diminished cognitive capacity because of degenerative brain disease or traumatic brain injury. For instance, 45 per cent of people aged 45 years or older in long-term residential care facilities have been diagnosed with dementia (Wong, Gilmour, \& RamageMorin, 2016). For the purposes of this article, we will refer primarily to residents with dementia, but our discussion has implications for those with other neurological conditions as well. A growing area of scholarship focuses on understanding cognitive capacity, navigating decision-making, and discerning consent for persons with dementia. One area of decision-making that is often overlooked is sexual expression. Despite significant contributions to the literature on sexuality, sexual expression, and sexual rights, little of this literature addresses those with diminished cognitive capacity residing in continuing care homes. This may result from assumptions that older adults and people with disabilities are sexually inactive or disinterested (Bauer, McAuliffe, \& Nay, 2007; Kontos, Grigorovich, Kontos, \& Miller, 2016; Kontula \& Haavio-Mannila, 2009).

Some recent scholarship has pushed back against these flawed assumptions and advanced an approach to understanding the agency and capacity of persons with dementia through a recognition of the agential status of embodied self-expression (Kontos et al., 2016) and/or a notion of relational autonomy (Bianchi, 2016). There is also an emerging conversation in popular culture about the challenges that dementia presents for matters of sexual consent (Bellemare, 2017; Bielski, 2018). However, part of the problem is that "in the context of mainstream values, the conjunction of disability and sexuality troubles the parameters of the social and legal policy" (Shildrick, 2007, p. 53). In order to support sexual expression for those with dementia in continuing care homes, one must contend with current practices and legislation related to guardianship.

In this article, we identify and explore several challenges associated with substitute decision-makers' (SDMs') involvement in continuing care residents' sexual expression. We focus on SDMs because they hold significant legal and practical decision-making responsibility, but have little to no preparation for doing so. Additionally, despite their considerable influence, SDMs are often omitted from conceptual literature on assessing capacity to consent to sexual activity. Our discussion is grounded in findings from a multi-phase qualitative study on sexual expression in continuing care homes in Alberta, Canada. Currently, Alberta does not have any policies related to sexual expression in continuing care.
We wondered how, in the absence of such policy, these matters are navigated. Across study phases 1 and 2, participants spoke about issues related to dementia, capacity, and consent. We noted that SDMs play a significant role in supporting or prohibiting resident sexual expression. Although the related legislation acknowledges that capacity admits of degrees, in practice it tends to be treated as all or none. This observation was echoed by several continuing care managers and direct care providers at subsequent knowledge-sharing events (personal communication, October 9; November 13, 2018). An "all-or-none" approach to competence implies that a person either has the requisite capacity for decision-making at large or they do not have any capacity. This approach can have negative implications for the sexual expression of residents with dementia. The ethical and conceptual problems associated with an all-or-none approach are well documented in related literature (Beauchamp \& Childress, 2009; Gordon, 2000; Leo, 1999; Stainton, 2016).

Most jurisprudential scholars now acknowledge that capacity admits of degrees. For instance, a person may be determined incompetent to prepare a will or select a particular medical treatment, but still be capable of determining if they wish to hold someone's hand. Our findings suggest that SDMs and continuing care staff may unwittingly employ the all-or-none approach to competence and, in turn, exacerbate difficulties with residents' sexual expression. Although our discussion focuses on Alberta, there is much reason to believe that these issues persist in other Western jurisdictions (within North America, Australia, and the United Kingdom, for instance) given their similar use of SDMs.

This article provides a critical review of existing legislation and empirical evidence of its challenges in practice. In what follows, we provide context for sexual expression in continuing care homes. We contend that three factors related to SDMs facilitate an environment in which the all-or-none approach to competence can influence and/or unduly limit continuing care residents' sexual expression. These three factors are (a) the wording of current legislation in Alberta - specifically, the Adult Guardianship and Trusteeship Act (2008) and Personal Directives Act (2000); (b) the lack of tools, resources, training, and supports for new SDMs; and (c) relational dynamics between SDMs and care staff. These factors can limit residents' sexual expression and prevent us from actualising potentially advantageous alternate models of capacity assessment and consent determination (Bellemare, 2017; Grigorovich \& Kontos, 2016; Kontos, Miller, \& Kontos, 2017). Lastly, we make several recommendations for how we can 
better support residents' sexual autonomy and avoid the pitfalls of the all-or-none approach.

\section{Background}

Agents and Continuing Care

In Alberta, continuing care homes include supportive living (SL) and long-term care (LTC). SL care homes provide residential settings with different levels of support services for residents with a range of needs and levels of independence. LTC homes (known elsewhere as nursing homes) provide 24-hour residential nursing and personal care for clients with more complex medical needs. Staff at these homes navigate a variety of situations that arise when caring for those with declining cognitive function and/or limited verbal expression. When residents with dementia are no longer able to make medical and other decisions for themselves, most Western jurisdictions employ the use of SDMs referred to as "agents" in Alberta.

Legislation grants agents the authority to make decisions on behalf of someone who has limited cognitive capacity. A continuing care resident selects their agent while they still have legal capacity, sometimes through the use of a personal directive document that outlines their future wishes (Government of Alberta, 2019). Typically, the agent is a spouse, partner, family member, or friend. The agent must be over 18 years of age and have a trusting relationship with the resident. Following a capacity assessment for the resident and a reference check and criminal background check for the agent, "guardianship" is appointed by a court (Government of Alberta, 2019). In the absence of a willing or available agent, the Office of the Public Guardian and Trustee may become the agent. Trusteeship focuses explicitly on decisions related to the resident's finances. An agent can be both guardian and trustee at the same time.

Agents must navigate health care decisions ranging from choices about medications and medical treatments to end-of-life options. However, agents can also make decisions related to residents' food, room and board, and the programs and/or services in which the resident is permitted to participate. Although more attention is typically paid to the clinical decisions that agents make, the non-clinical decisions can have profound effects on residents' health, well-being, and quality of life.

\section{Sexual Expression in Continuing Care Homes}

The term "sexual expression" refers to a broad spectrum including sexual behaviour, emotional intimacy, sensual activity, and sexual identity (Hillman, 2000).
Examples of sexual expression may include grooming and self-presentation, handholding, masturbation, use of pornographic materials or sexual aids, cuddling or embracing, art and recreation (visual, dance, etc.), and sexual encounters, including intercourse (Doll, 2012). The World Health Organization recognises a crucial connection between sexuality and health, and that sexual expression can contribute to people's sense of wellbeing (World Health Organization, 2015). As recent conversations in Canadian news reporting have indicated (Bellemare, 2017; Bielski, 2018), dementia does not eliminate sexual interest. It is well documented that continuing care residents with dementia still think about and desire sex and intimacy, and display sexual preferences (Ehrenfeld, Bronner, Tabak, Alpert, \& Bergman, 1999; Kuhn, 2002; Mahieu, Anckaert, \& Gastmans, 2017; Makimoto, Kang, Yamakawa, \& Konno, 2015). Continued interest and participation in sexual activity can also be therapeutic for older adults (Kontula \& Haavio-Mannila, 2009). Despite this, sexual expression can be a particularly challenging field of decisionmaking for agents to navigate.

Agents may experience challenges associated with discomfort with the topic, diverse attitudes and beliefs about sexual expression, ignorance regarding a resident's needs and preferences, limited information regarding dementia and sexual expression, varying degrees of knowledge and education of health care staff, and/or societal assumptions of asexuality for older adults and those with chronic health conditions (Bauer et al., 2014). One study found that staff and family members often make decisions about residents' sexual expression without consulting the resident (Frankowski \& Clark, 2009). This is troublesome because residents typically want to make their own decisions about sexual expression, without the involvement of families or care providers (Bauer et al., 2012). This is not to say that there is no place for agents in these matters. Agents can act as advocates to protect residents from unwanted sexual advances or assist staff with interpreting expressions and/or navigating aggressive or public sexual behaviours (e.g., by recommending redirection strategies or providing supports). However, the manner in which current legislation is taken up can create uncertainty with respect to how, and over what, agents should exercise their decisional authority. In the following section, we outline the methods used to collect data on sexual expression in continuing care.

\section{Methods}

The data included in this article come from two phases of a broader study we conducted on sexual expression 
in Alberta's continuing care homes. In Phase 1, we interviewed continuing care home managers and those whom they consult (clinical ethicists, best practice/ geriatric assessment teams, social workers, and others in regional leadership positions) about matters related to sexual expression. In Phase 2, we interviewed continuing care residents and family members (not all of whom were SDMs). Across both data sets, we heard about the substantive role that SDMs play in decisions around resident sexuality.

We received ethics approval for this research from our institutional Research Ethics Office and operational approvals from relevant care provider agencies. We used a qualitative exploratory design (Hesse-Biber \& Leavy, 2011) to identify how, in the absence of related provincial policies, managers navigate resident sexual expression in continuing care settings and how residents and family members feel about this topic. Our samples for both phases included participants from each of the five provincial health zones, with a mix of urban, suburban, and rural care homes.

In the presence or absence of policy, managers coordinate decision-making and shape the culture of a care home. These individuals have the authority to shape site-level responses to sexual expression. For this reason, we recruited continuing care managers and those whom they consult to participate in Phase 1. Participants were recruited at regularly scheduled managers' meetings and through Alberta Health Services (AHS) administrative assistants, who disseminated the invitation via e-mail. Prospective participants contacted the research team to indicate their interest. Data collection took place between December 2017 and July 2018. We conducted semi-structured interviews with 28 participants over the telephone or in person. We interviewed 13 managers, four clinical ethicists, four geriatric specialty team members, four regional directors, two social workers, and one physician who does related consulting. All of the participants had worked in their role for at least two years. We asked participants about existing policies and practices, challenges, exemplary cases, and supports that may be useful for navigating sexual expression.

Data collection for Phase 2 took place between May 2018 and March 2019. We recruited residents and family members via posters in care homes, e-mail listservs, caregiver support groups, and direct e-mails to recreation therapists and care home managers who then shared study information at resident and family council meetings. We interviewed 20 participants -12 residents and eight family members (over the telephone and in-person). We asked about how participants defined sexual expression, the kinds of conversations that they have had or think are needed related to sexual expression in continuing care, their preparedness for this aspect of life/care, and the types of supports that would be useful to them. Few residents spoke about matters related to SDMs because, in order to consent to participate in our study, they had to be their own decisionmakers. The interviews for both phases were digitally recorded and lasted between 45 and 75 minutes. The transcribed interviews were coded and critically analysed using Braun and Clarke's (2006) approach to thematic analysis. "Dementia, capacity, and consent" was identified as a theme in both data sets.

When this theme was identified, we sought out policy and legal documents regarding substitute decisionmaking in Alberta. The documents included the Alberta's Personal Directives Act (2000), the Adult Guardianship and Trusteeship Act (2008), and a review of these acts produced by the Alberta Justice and Alberta Seniors and Community Supports groups (2005). Atkinson and Coffey (1997) referred to documents as, "'social facts' that are produced, shared, and used in socially organised ways" (p. 47). We examined these "facts" in order to gain a deeper understanding of how substitute decision-making is understood and enacted. In other words, we were interested in both the documents' function and content (Prior, 2008). We selected these documents because they provide and review the legal framework for substitute decision-making in the province. Each author read and reviewed these documents independently; we discussed them as a team and included them to establish the context in which research participants operate.

\section{Findings}

In this section, we examine three factors that enable the all-or-none approach. These include (a) the wording of current Albertan legislation, (b) the lack of resources or supports for agents, and (c) relational dynamics between care staff and agents.

\section{Relevant Legislation in Alberta}

The process for capacity determination in Alberta recognises several domains of decision-making: medical treatments, accommodation, and leisure and socialisation (Government of Alberta, 2000). Following the determination of incapacity in any or all domains, it is incumbent on the agent to make decisions on behalf of the resident. When a person is declared incompetent in one or more domains, Alberta's Personal Directives Act states that "unless a personal directive provides 
otherwise, [the] agent has authority to make personal decisions on all personal matters of the maker" (Government of Alberta, 2000, p. 12). Separately, the Adult Guardianship and Trusteeship Act (2008), which details the terms of a guardianship order, specifies areas within the purview of the agent. This includes areas such as where the adult lives, with whom they associate, their participation in leisure pursuits, and health care (Government of Alberta, 2008). This is problematic because the multi-domain assessment still produces a fixed designation of capacity - effectively treating it as all-or-none.

An all-or-none approach may be enabled when agents have authority in these broadly defined areas, but lack a nuanced explanation of how, when, and in what circumstances that authority ought to be exercised. This can mistakenly remove the resident from participating in decisions about their life. For example, a family member told us about a care conference regarding her father's use of pornography (a conference to which her father was not invited):

\begin{abstract}
His nurse, she's like, "This is his choice and if he's doing it, then here's what we figure out to manage it, but you can't actually force him to do what you want"... afterwards, I said to him, "I'm sorry. I probably should have come to get you" and he was nodding. I think that's the danger with continuing care settings. I'm probably someone who has a fairly high degree of consciousness around that and it was still so easy to just kind of steamroll in and not have him involved [in] one of the more important meetings around how his life unfolds. So, when it comes to sexual expression, that those conversations have the potential to happen without the person is really scary ... I mean, I want my dad to be able to watch porn. I mean, I don't want him to be able to watch porn, but I want him to be able to do as much as he can in his space that is his space. (Family member)
\end{abstract}

This participant revealed how easy it was to omit her father from decision-making about his sexual expression. Although this particular participant expressed regret about how events transpired, the legislation's wording around leisure and socialisation may give agents the impression that it is acceptable for them to make decisions regarding all of the resident's personal matters. Agents are not alone in their struggles to understand the boundaries between domains of capacity. Another participant, a social worker who is trained as a capacity assessor, told us:

So, when I get consulted around issues of intimacy and sexuality and consent, I'm doing it as a consultant. I can't actually do a capacity assessment specific to sexual consent, because it doesn't fit within the Adult Guardianship and Trusteeship Act. So, when I've been asked "Which domain does it fit into?" I have to ask, "Okay, what are you actually asking for? Do you feel that the individual has the ability to consent around associations, like, their social connections? That's a domain. Are you asking if this individual can consent to being in a romantic or intimate relationship with an individual? Or is it about, can they consent to being sexually intimate? Because that leans more towards health care, because there's physical consequences to various sexual acts. Or is it about their legal - like can they say "no," and do they understand yes and no?" So, it's kind of muddled, because again, intimacy and sexuality cover all of those domains, it's not this fine line. (Social worker)

The review of the Alberta Dependent Adults Act and Personal Directives Act also identified the acts' shortcomings in recognising the fluctuating nature of capacity and the challenges with assessing it across domains. The reviewers could not reconcile operational challenges of this approach and favored the re-assessment of capacity at intervals suitable to the individual's circumstance (Alberta Justice \& Alberta Seniors \& Community Supports, 2005). This review also argued that a new act should identify the responsibilities and duties of all levels of SDMs in a more detailed fashion. The reviewers suggested that, where possible, decisions ought to be made in consultation with the resident as opposed to independently by the agent (Alberta Justice \& Alberta Seniors \& Community Supports, 2005). This is crucial because it acknowledges that the goal of substitute decision-making should be to promote as much agency as possible. At the time of writing, the acts have not been amended to incorporate these recommendations.

\section{Lack of Resources, Supports, or Training for New Agents}

Many agents find themselves in this role without any experience, training, or education related to substitute decision-making. Currently, aside from calling the Office of the Public Guardian, there are limited resources to support new agents with this responsibility. When we asked Phase 1 participants about resources for SDMs and residents' family members, they had very few suggestions:

Interviewer: And are there any resources available that you can provide for agents in that situation? 
Respondent: Hmm. Can't think of any off the top of my head to be honest. No, I mean, I've been in the system for a long time and I can't think of anything, to be honest with you. (Manager 1)

Interviewer: You mentioned something about education and training. What education and training opportunities are available, that you're aware of?

Respondent: Not a lot. For family members? I don't know. The Alzheimer's Society?

\section{(Best Practices Team Member 1)}

Without supportive resources and/or education and training opportunities, it can be unclear as to what it means to be an agent for someone else. Agents may have misconceptions about when and to what extent they should make decisions on the residents' behalf. Some participants explicitly stated the need to clarify this role:

[T] answer your question around that, how do you help families? Frame their job correctly from the beginning. Most of the problems I have to deal with are because we've let family members overstep their bounds ... and then they consult me, and I say, "Well, that's inappropriate. Out of respect for this patient's autonomy we shouldn't do that." Well, now, how do you change that behaviour when they've had [it] for the last year? So helping people right from the get-go is that, "Here's your role as guardian or decision-maker for this patient and here's the boundaries." (Ethicist 1)

The clearest guidelines that articulate the role of agents come from the Adult Guardianship and Trusteeship Act of Alberta (2008), which states that "in determining whether a decision is in an adult's best interests, consideration must be given to (i) any wishes known to have been expressed by the adult while the adult had capacity, and (ii) any values and beliefs known to have been held by the adult while the adult had capacity" (p. 11). These considerations are important, but may not be sufficient in the case of sexual expression. The reasons for this are twofold. First, relatives are not often privy to the sexual desires, practices, and preferences of their kin. These desires, practices, and preferences are often kept private and may be an uncomfortable topic of conversation for families. Second, even if the agent was previously privy to the sexual desires and preferences of the now cognitively impaired resident (e.g., if the agent is a partner or spouse), these practices and preferences are prone to changing over time and/or with a diagnosis of dementia.

Given that these are the clearest guidelines available, it would be easy for a new agent to think that they are primarily expected to make decisions that best align with the resident's past wishes and values. However, this ambiguity can once again facilitate the all-or-none approach. In an attempt to make decisions consistent with a resident's past desires and values, any new or different choices made by the resident can be dismissed or regarded as being the result of dementia. A clinical ethicist told us about how rare it is for agents to consider seriously the residents' current sexual interests:

\begin{abstract}
A case I recently had, the daughter was the patient's agent ... It obviously was hard for her, but she said, "My mother would be horrified to see herself behaving like this, but that person is no longer here. And for the woman here, my mother that's here in the facility, sexuality is very important for her." And so that's a rare daughter that can so thoughtfully and generously understand the needs of her mother. So often families will say, "I'm not going to let my dad do that. I'm not going to let my mom do that." And they hold them to standards that they knew when the person was fully competent. (Ethicist 2)
\end{abstract}

It is important that agents recognise their role as more than merely expressing the prior desires or values of the resident. They hold a responsibility to maximise the resident's current agency. Others have also identified the need for a clearer description of agents' responsibilities. For instance, the review of the Alberta Dependent Adults Act and Personal Directives Act states that a new act that sets out the duties of all levels of SDMs should include informing them about the nature of their role and responsibilities (Alberta Justice \& Alberta Seniors \& Community Supports, 2005). Agents would be better served with resources and educational materials that clearly outline the boundaries of their roles and support them in shared decision-making. This clarity would also benefit continuing care home staff, who regularly interact with agents and are legally responsible for residents' welfare.

\section{Relational Dynamics Involving Care Staff and Agents}

In addition to the wording of legislation and the lack of preparation for new agents, relational dynamics involving care staff and agents may also lend themselves to the enabling of the all-or-none approach to competence. In absence of clearly defined roles and responsibilities, staff may excessively defer to agents for decisional tasks 
involving the resident. This can also stem from a desire to avoid complaints from families or to avoid potential legal liability:

I've also had conversations with families, and this is kind of what we've always done if they [had dementia], I've said to family, "You give me the direction. Are you okay with it? Or like, what do you want? Do you want us to put them on different units to kind of split [the residents and their relationship] up?" So that's kind of how we've done things with people that are lacking the ability to make decisions. (Manager 2)

I remember one situation where the family just put their foot down and the residents [who were in a romantic relationship] had to be separated. That was a case of the situation being beyond our control. You know, the person had an agent and there was very little we could do. I mean, it broke our hearts actually to have to step in and do that, but, you know, that's part of being the staff; if the agent says "no", then legally that's what we have to do. (Manager 3)

In both of these scenarios, agents informed the care staff about their wishes to keep residents out of romantic relationships. This suggests that agents are often involved in "managing" residents' sexual expression in ways that they are not involved with other activities of daily living. One participant indicated a need for greater clarity about the division of decision-making responsibilities between agents and care staff:

What many people don't realise is, just because you may be someone's guardian, that doesn't mean that you can tell a physician or a nurse how medication is going to be administered. And so, care providers often allow that to happen [with sexual expression] because, "Oh, they're the family." And so the boundaries of what [family] can legitimately have an opinion on is an issue as well. (Ethicist 2)

There are many good reasons for agents to have a say in what happens to their relative in continuing care settings. However, the lack of clarity about the scope of an agent's role can lead to scenarios in which staff defer to agents without including the resident in decisionmaking. This may be especially true when care providers are hurried, overworked, and/or burnt out (Knopp-Sihota, Niehaus, Squires, Norton, \& Estabrooks, 2015) and have little time to navigate these issues.

Having an SDM can have negative implications for sexual expression when agents are especially permissive or especially restrictive in their approaches. An example of the former would be instances in which there is insufficient assessment of a resident's willingness to participate in sexual activity. Several Phase
1 participants indicated that this can be an issue for staff when the agent is also the resident's partner:

If [visiting husband who is the agent] wants a Do Not Disturb sign, we don't know what he wants to do at that point. And, l'd like to say it's none of our business, but if he's causing stress to our resident who's going to be upset and have trauma and behaviours later, are we giving good care? So, there would be quite a lot of discussion and might even become an ethical consult. (Manager 4)

If they're in a relationship and it's being allowed, well, there may be that day where the resident's not consenting to it. Like anybody, "I'm not in the mood." but they've got dementia. The gentleman may not understand and he's trying to escort her back to the room and she's saying, "No." There's going to be on and off days too, where yes, generally, they're involved in this relationship and enjoying it and benefitting from it, but there will be the days they're not feeling good and maybe the gentleman doesn't understand that. Or the visiting husband is the agent and gets to decide for her. (Best Practices Team Member 2)

Interviewer: Are you ever consulted if the agent is the spouse or partner of the resident and they're seeking a sexual relationship?

Respondent: Yes. And we've had cases here where we felt it was entirely inappropriate and that there was an abusive aspect to it, even if there wasn't an intent. We have actually had to go to the Office of the Public Guardian and make a complaint. (Social worker)

These scenarios illustrate the dual roles experienced by the agent (as lover and as SDM). These two roles can come into conflict when the agent is both seeking and granting the resident's consent to sexual activity. Staff may understand that an agent wants to maintain a romantic and/or sexual relationship with their partner, but may also become concerned that the agent has a conflict of interest in assessing consent. When they do not include the resident in this decision-making, the staff and agent may err on the side of permissiveness.

Family concerns can also be used to justify restrictions upon residents' rights to sexuality (Barmon, Burgess, Bender, \& Moorhead Jr., 2017). An example of an especially restrictive approach is when the agent's decision to prohibit sexual expression is at odds with the resident's expressed desires. For instance, it is common for persons living with dementia in continuing care to 
develop new relationships with fellow residents, sometimes while they are married or in committed partnerships (Doll, 2013; Wiskerke \& Manthorpe, 2018). This can be upsetting for community-dwelling spouses or partners who may then request that the new relationship be discontinued or that one of the residents be moved - both of which can be difficult for residents. New relationships formed in continuing care homes can also be challenging for residents' progeny (Bauer et al., 2014). When an adult child is the agent, they may restrict their parent's sexual expression because of an image of their parent as asexual, because of personal views about the new relationship and/or partner, because of perceptions of inappropriateness of sexual expression in continuing care contexts, and more. For instance, we heard that adult children will intervene to ensure their parent's fidelity to a living or a deceased spouse, and that these decisions are also informed by concerns about their parent's reputation:

[T] hey're the agents, they're the ones who are making those types of decisions. I mean, we do our best to, sort of, educate the family to say, "They don't realise that they're married to somebody in the community. I understand that it's your mother, but you know, people have a need for closeness" and that sort of thing. We do our best, but sometimes agents just say, "No. Keep them apart". (Manager 1)

And if you're in a small-town care facility, word gets out. Oh, you know, "Frank's dad - oh my God, you should see him", and it affects the family. So they have a lot invested in managing the resident's behaviour. (Ethicist 2)

These restrictions privilege the views, values, and preferences of the agent, despite indication of the resident's wishes. This can deprive the resident of regular opportunities for meaningful connection and intimacy.

The number of parties involved in residents' choices, the taboo nature of the subject, and the nuances of the decision-making itself contribute to relational dynamics that are complex and fraught. Decisions about sexual expression are thus, bound up with family and social histories, as well as care-setting dynamics.

\section{Conclusion and Recommendations}

Considerable evidence suggests that capacity fluctuates and admits of degrees (Beauchamp \& Childress, 2009; Gordon, 2000; Leo, 1999; Stainton, 2016). Albertan legislation recognises this to be true. However, our findings suggest that in practice, capacity can be treated as all-ornone. This poses challenges for continuing care residents' sexual expression - namely, that agents sometimes end up with too much decisional authority and can be too permissive or too restrictive in their approach. Agents can neglect to involve the resident in decision-making or err on the side of past wishes without sufficient consideration of the individual's current desires. In many cases, this may simply result from the fact that substitute decision-making is incredibly complex and not well understood. We heard that the existing resources to support agents in navigating these matters are insufficient. Our findings suggest that, at present, existing principles about including residents in decision-making are aspirational. Both managers and agents have expressed difficulty with operationalising them.

In this article, we have argued that three factors contribute to the treatment of capacity as all or none. These include the wording of current legislation, the lack of resources for SDMs, and the relational dynamics between SDMs and care staff. Given their similar use of SDMs, our findings and recommendations may have implications for those in other Western jurisdictions as well. We recommend an integrated approach that responds to these challenges.

\section{Wording of Current Legislation}

We recommend amending the Albertan legislation on guardianship for persons with diminished cognitive capacity. One way to do this would be to take up existing recommendations for improvement. As noted earlier, the changes recommended in the review of the Alberta Dependent Adults Act and Personal Directives Act (Alberta Justice \& Alberta Seniors \& Community Supports, 2005) have not yet been implemented. It is not too late to do so. Our findings provide a compelling case for the need to revise the act(s) in order to address concerns about residents' agency and sexual expression. The amendments would more clearly identify what it means to be an agent (including the boundaries and scope of the role), reassessment of capacity at intervals relevant to the resident's circumstances, and consulting the resident in decision-making, rather than making decisions independently on their behalf.

Furthermore, we recommend that Albertan legislators look to jurisdictions that are taking leadership on this issue. For instance, our neighbouring province, British Columbia, has a highly developed approach to capacity and decision-making via their landmark Representation Agreement Act (British Columbia Representation Agreement Act, 1996). The act (1996) stipulates that a "representative" shall not take the place of the individual. Rather, they must act as an intermediary to help third parties understand and interact with the individual. As Stainton (2016) observed, this act's central 
strength is realised through the representatives' imperative to support self-determination and participation in decision-making and to discern the individual's wishes based on knowledge of the person, how they communicate (traditional and non-traditional forms), and their socio-cultural context. Therefore, the representative must take the time to understand how the individual communicates beyond verbalisation and make sense of the overt and covert meanings of behaviours and body movements. Such a responsibility is powerful because it both foregrounds the individual's fullest participation in decision-making and attends to the nuance of how preferences are conveyed.

\section{Resources to Support SDMs}

We recommend developing additional resources that prepare agents for this role. Several Phase 2 participants indicated that information packages and brochures would be helpful for initiating conversations about sexual expression with residents' family members and would help to educate them about how dementia might affect sexual expression. An information package about what it means to be an agent would complement other brochures on this topic and the revised legislation. These packages could be provided by the Office of the Public Guardian when someone is appointed as an agent and then later reviewed with a member of the care team when a resident moves into a continuing care home. These resources would help to clarify how the agent and the resident fit into the matrix of decision-making.

\section{Relational Dynamics between SDMs and Care Staff}

In addition to legislative changes and developing resources for agents, we also recommend developing site-level guidelines, in the form of a care home policy on sexual expression. Each care home should be required to develop a policy on sexual expression (to uphold human rights to non-discrimination, to protect residents from unwanted expressions, to indicate what kind of privacy is available to residents, and more). Because each care home would be responsible for developing the policy themselves, they would also have the flexibility to tailor it to their site's specific needs (Doll, 2012). Among other things, these site-level policies should encourage collaborative decision-making based on the best interpretation of a resident's current wishes, their past expressed desires, the agent's reading of the situation, and the staff's professional assessment.

Taken together, this integrated approach foregrounds residents' agency as much as possible, clarifies an agent's role, guides direct care staff to make resident- focused decisions, and works to ensure that expressions of sexuality are safe and dignified.

\section{References}

Alberta Justice \& Alberta Seniors \& Community Supports. (2005). Legislative Review of the Dependent Adults Act and the Personal Directives Act: Stakeholders Consultation Summary. Calgary, AB: Author. Retrieved from http:/ / www.assembly.ab.ca/ lao/library/egovdocs/2006/als/155963.pdf

Atkinson, P. A., \& Coffey, A. (1997). Analysing documentary realities. In D. Silverman (Ed.), Qualitative research: Theory, method and practice (pp. 45-62). London, ENG: Sage.

Barmon, C., Burgess, E. O., Bender, A. A., \& Moorhead, J. R., Jr. (2017). Understanding sexual freedom and autonomy in assisted living: Discourse of residents' rights among staff and administrators. The Journals of Gerontology. Series B, Psychological Sciences and Social Sciences, 72(3), 457-467. doi:10.1093/geronb/gbw068

Bauer, M., Fetherstonhaugh, D., Tarzia, L., Nay, R., Wellman, D., \& Beattie, E. (2012). "I always look under the bed for a man." Needs and barriers to the expression of sexuality in residential aged care: The views of residents with and without dementia. Psychology and Sexuality, 4(3), 296-309. doi:10.1080/19419899.2012.713869

Bauer, M., McAuliffe, L., \& Nay, R. (2007). Sexuality, health care and the older person: An overview of the literature. International Journal of Older People Nursing, 2(1), 63-68. doi:10.1111/j.1748-3743.2007.00051.x

Bauer, M., Nay, R., Tarzia, L., Fetherstonhaugh, D., Wellman, D., \& Beattie, E. (2014). 'We need to know what's going on': Views of family members toward the sexual expression of people with dementia in residential aged care. Dementia, 13(5), 571-585. doi:10.1177/1471301213479785

Beauchamp, T., \& Childress, J. (2009). Principles of biomedical ethics. New York, NY: Oxford University Press.

Bellemare, A. (2017). Can you consent to sex if you have dementia? Researcher studies dilemma. CBC News. Retrieved from https://www.cbc.ca/news/canada/ kitchener-waterloo/sex-dementia-consent-researchwaterloo-andria-bianchi-1.4044539

Bianchi, A. (2016). Autonomy, sexuality, and intellectual disability. Social Philosophy Today, 32, 107-121. doi:10. 5840 / socphiltoday20168232

Bielski, Z. (2018). Grey area: The fragile frontier of dementia, intimacy and sexual consent. The Globe and Mail. Retrieved from https: / / www.theglobeandmail.com/canada/articlegrey-area-the-fragile-frontier-of-dementia-intimacy-andsexual/

Braun, V., \& Clarke, V. (2006). Using thematic analysis in psychology. Qualitative Research in Psychology, 3(2), 77-101. doi:10.1191/1478088706qp063oa 
British Columbia Representation Agreement Act. (1996). Statutes of British Columbia, 1996, Chapter 405. Victoria, BC: British Columbia Queen's Printer.

Doll, G. (2012). Sexuality E long-term care: Understanding and supporting the needs of older adults. Baltimore, MD: Health Professions Press.

Doll, G. (2013). Sexuality in nursing homes: Practice and policy. Journal of Gerontological Nursing, 39(7), 30-37. doi:10.3928/00989134-20130418-0

Ehrenfeld, M., Bronner, G., Tabak, N., Alpert, R., \& Bergman, R. (1999). Sexuality among institutionalised elderly patients with dementia. Nursing Ethics, 6(2), 144-149. doi:10.1191/096973399677350269

Frankowski, A., \& Clark, L. (2009). Sexuality and intimacy in assisted living: Residents' perspectives and experiences. Sexuality Research and Social Policy, 6(4), 25-37. doi:10. 1525 /srsp.2009.6.4.25

Gordon, R. (2000). The emergence of assisted (supported) decision-making in the Canadian law of adult guardianship and substitute decision-making. International Journal of Law and Psychiatry, 23(1), 61-77. doi:10.1016/s0160-2527(99)00034-5

Government of Alberta. (2000). Statutes of Alberta. Personal Directives Act. Edmonton, AB: Author. Retrieved from http:/ / www.qp.alberta.ca/documents/Acts / p06.pdf

Government of Alberta. (2008). Statutes of Alberta. Adult Guardianship and Trusteeship Act. Edmonton, AB: Author. Retrieved from http://www.qp.alberta.ca/ documents / Acts / A04P2.pdf

Government of Alberta. (2019). Adult guardianship. Retrieved from https://www.alberta.ca/adult-guardianship. aspx\#toc-1

Grigorovich, A., \& Kontos, P. (2016). Advancing an ethic of embodied relational sexuality to guide decision-making in dementia care. The Gerontologist, 58(2), 219-225. doi:10. 1093/geront/gnw137

Hesse-Biber, S., \& Leavy, P. (2011). The practice of qualitative research (2nd ed.). Los Angeles, CA: Sage.

Hillman, J. L. (2000). Clinical perspectives on elderly sexuality. New York, NY: Springer.

Knopp-Sihota, J. A., Niehaus, L., Squires, J. E., Norton, P. G., \& Estabrooks, C. A. (2015). Factors associated with rushed and missed resident care in Western Canadian nursing homes: A cross sectional survey of health care aides. Journal of Clinical Nursing, 24(19-20), 2815-2825. doi:10. 1111/jocn.12887
Kontos, P., Grigorovich, A., Kontos, A. P., \& Miller, K. (2016). Citizenship, human rights, and dementia: Towards a new embodied relational ethic of sexuality. Dementia, 15(3), 315-329. doi:10.1177/1471301216636258

Kontos, P., Miller, K., \& Kontos, A. (2017). Relational citizenship: Supporting embodied selfhood and relationality in dementia care. Sociology of Health $\mathcal{E}$ Illness, 39(2), 182-198. doi:10.1111/1467-9566.12453

Kontula, O., \& Haavio-Mannila, E. (2009). The impact of aging on human sexual activity and sexual desire. Journal of Sex Research, 46(1), 46-56. doi:10.1080/00224490802624414

Kuhn, D. (2002). Intimacy, sexuality, and residents with dementia. Alzheimer's Care Quarterly, 3(2), 165-176.

Leo, R. J. (1999). Competency and the capacity to make treatment decisions: A primer for primary care physicians. The Primary Care Companion to the Journal of Clinical Psychiatry, 1(5), 131-141. doi:10.4088\%2Fpcc.v01n0501

Mahieu, L., Anckaert, L., \& Gastmans, C. (2017). Intimacy and sexuality in institutionalized dementia care: Clinicalethical considerations. Health Care Analysis, 25(1), 52-71. doi:10.1007/s10728-014-0287-2

Makimoto, K., Kang, H. S., Yamakawa, M., \& Konno, R. (2015). An integrated literature review on sexuality of elderly nursing home residents with dementia. International Journal of Nursing Practice, 21(Suppl. 2), 80-90. doi:10.1111/ijn.12317

Prior, L. (2008). Repositioning document in social research. Sociology, 42(5), 821-836. doi:10.1177/0038038508094564

Shildrick, M. (2007). Contested pleasures: The sociopolitical economy of disability and sexuality. Sexuality Research and Social Policy, 4(1), 53-66. doi:10.1525/srsp.2007.4.1.53

Stainton, T. (2016). Supported decision-making in Canada: Principles, policy, and practice. Research and Practice in Intellectual and Developmental Disabilities, 3(1), 1-11. doi: 10.1080/23297018.2015.1063447

Wiskerke, E., \& Manthorpe, J. (2018). New relationships and intimacy in long-term care: The views of relatives of residents with dementia and care home staff. Dementia, 17(4), 405-422.

Wong, S. L., Gilmour, H., \& Ramage-Morin, P. L. (2016). Alzheimer's disease and other dementias in Canada. Health Reports. Statistics Canada Catalogue no. 82-003-X. Ottawa, ON: Statistics Canada.

World Health Organization. (2015). Sexual health, human rights and the law. Retrieved from http://apps.who.int/iris/ bitstream/10665/175556/1/9789241564984_eng.pdf 